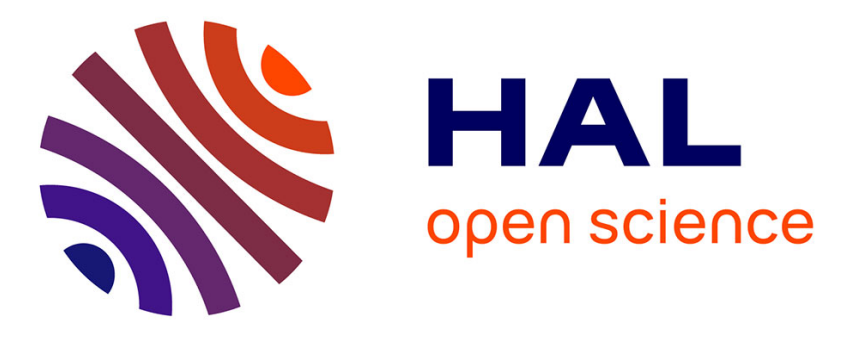

\title{
Microsatellite markers reveal two genetic groups in European populations of the carrot cyst nematode Heterodera carotae
}

Camille Gautier, Magali Esquibet, Sylvain Fournet, Christophe Piriou, Jean-Claude Yvin, Eric Nguema-Ona, Eric Grenier, Josselin Montarry

\section{To cite this version:}

Camille Gautier, Magali Esquibet, Sylvain Fournet, Christophe Piriou, Jean-Claude Yvin, et al.. Microsatellite markers reveal two genetic groups in European populations of the carrot cyst nematode Heterodera carotae. Infection, Genetics and Evolution, 2019, 73, pp.81-92. 10.1016/j.meegid.2019.04.011 . hal-02291476

\section{HAL Id: hal-02291476 \\ https://hal.science/hal-02291476}

Submitted on 22 Oct 2021

HAL is a multi-disciplinary open access archive for the deposit and dissemination of scientific research documents, whether they are published or not. The documents may come from teaching and research institutions in France or abroad, or from public or private research centers.
L'archive ouverte pluridisciplinaire HAL, est destinée au dépôt et à la diffusion de documents scientifiques de niveau recherche, publiés ou non, émanant des établissements d'enseignement et de recherche français ou étrangers, des laboratoires publics ou privés.

\section{(c) (1) $\$$}

Distributed under a Creative Commons Attribution - NonCommercial| 4.0 International 


\section{Microsatellite markers reveal two genetic groups in European populations}

\section{2 of the carrot cyst nematode Heterodera carotae}

3

4 GAUTIER Camille ${ }^{1,2}$, ESQUIBET Magali ${ }^{1}$, FOURNET Sylvain ${ }^{1}$, PIRIOU Christophe ${ }^{1}$,

5 YVIN Jean-Claude ${ }^{2}$, NGUEMA-ONA Eric ${ }^{2}$, GRENIER Eric ${ }^{1}$ and MONTARRY Josselin ${ }^{1}$

6

$7 \quad{ }^{1}$ IGEPP, INRA, Agrocampus-Ouest, Université de Rennes 1, 35650, Le Rheu, France

$8 \quad{ }^{2}$ Centre Mondial de l'Innovation-Laboratoire de Nutrition Végétale Pôle Biocontrôle, Groupe

9 Roullier, Saint Malo, France

10

11

*Corresponding author: gautier.camille@orange.fr 


\section{SUMMARY}

The cyst nematode Heterodera carotae, which parasitizes carrot roots, has been recorded in many countries in Europe (Italy, The Netherlands, Switzerland, France, Denmark, ...), in South Africa and in North America (Canada, USA). To date, there is a lack of knowledge about the genetic structure of the populations of this economically important nematode. The aim of this work was to study the structuration of the genetic diversity of the carrot cyst nematode at the European scale. We have developed a set of thirteen polymorphic microsatellite markers and used it to genotype seventeen European populations of $H$. carotae coming from France, Switzerland, Italy, Denmark and one non-European population from Canada. As previously showed for other cyst nematode species, the $H$. carotae populations were characterised by a strong heterozygote deficit. A Bayesian clustering analysis revealed two distinct genetic clusters, with one group located in the north of Europe and a second one located in the south of Europe. Moreover, our results highlighted rather limited gene flow at small spatial scale and some events of long distance migration. This first investigation of the genetic diversity of $H$. carotae populations would be useful to develop sustainable control strategies.

Keywords: Daucus carota; Genetic diversity; Heterozygote deficit; Isolation By Distance, Phytoparasitic nematode; SSR markers 
- A set of 13 polymorphic microsatellite markers was developed for $H$. carotae

- High heterozygote deficit was found among populations

- Genetic diversity was structured into two clusters: a north group and a south group at the European scale

- Significant isolation by distance pattern was highlighted between $H$. carotae populations 


\section{INTRODUCTION}

Population genetics have been applied to diverse plant-parasitic pest and pathogen species (Milgroom, 2015). These studies are of particular importance to understand disease evolution, host parasite interactions and to design efficient control methods against plant parasites. Predicting of where, when and how fast adaptation may occur, is a very challenging scientific question and has also strong practical interest (Lebarbenchon et al., 2008). The extent and speed of adaptation processes depend on species and/or population life history traits including dispersal abilities, population size and reproduction mode. These features strongly contribute to the genetic diversity level in pest populations and therefore, to their ability to adapt to control methods (e.g. phytosanitary products and plant resistances) and environmental conditions. Population genetic approaches allow to estimate the evolutionary potential of a pest and help to predict how and in which conditions, adaptation may appear and spread in populations (McDonald and Linde, 2002). As a result investigating the genetic diversity of plant-parasitic populations, at different spatial scales, could help to predict the potential efficiency and durability of control methods and also to give some new information about the evolutionary history of pest populations.

Plant-parasitic nematodes are harmful pests of cultivated crops causing important economic losses to a wide variety of crops, estimated at \$US 100 billion (Bird and Kaloshian, 2003; Nicol et al., 2011). Most of the damages are caused by some species belonging to two major groups, root-knot nematodes such as Meloidogyne spp. and cyst nematodes such as Heterodera and Globodera spp (Molinari, 2011). Among the different solutions to control plant-parasitic nematodes, chemical nematicides, such as the fumigant methyl bromide or the dichloropropane, are the most efficient, but many of them have already been banned in France and Europe and withdrawn from the market due to their harmful effects on human health and the environment (Oka et al., 2000). These regulatory changes promote alternative control 
solutions, such as biocontrol solutions and an extensive use of plant resistances. There is already some strong evidences of the adaptive potential of nematodes and in particular for cysts nematodes species to the use of resistant plants (Fournet et al., 2013; Niere et al., 2014; Phillips and Blok, 2008), but also some evidences that such adaptive abilities can be different between populations and strongly correlated to their evolutionary history (e.g. Zaheer et al. (1993) and Castagnone-Sereno et al. (2015) for nematodes and Xhaard et al. (2012; 2011) for a fungus).

Cyst nematodes are sedentary endoparasites of plants with a survival stage, the cyst, which is the body hardened of dead female containing eggs. Basically, second-stage juvenile (J2) hatch from the cyst thanks to the perception of root exudates released by the host plant (Perry, 1986). The juveniles migrate freely into the soil to the root tip and penetrate inside to establish a feeding site, the syncytium, which is an important nutrient sink for the plant (Jones and Northcote, 1972). Nematodes realize successive moults through the third (J3) and fourth (J4) stages to become either male or female. Adult males leave the root in order to mate females, which are growing through burst on the epidermal layers of the root and become visible on the root surface. After mating, females die and form a cyst (their cuticle turns brown and hardens) that remains in the soil after harvest. The cyst constitutes an effective stage to spread and survive in which juveniles stay viable for several years in the soil (Lilley et al., 2005).

The genetic structure and the evolutionary history of several cyst nematodes have been previously studied at different spatial scales, e.g. the potato cyst nematodes Globodera pallida (Eves-van den Akker et al., 2015; Picard et al., 2004; Picard et al., 2007; Plantard et al., 2008) and G. rostochiensis (Boucher et al., 2013; Mimee et al., 2015), the tobacco cyst nematode $G$. tabacum (Alenda et al., 2014; Marché et al., 2001), the beet cyst nematode Heterodera schachtii (Kim et al., 2018; Plantard and Porte, 2004), the cereal cyst nematode H. avenae 
(Wang et al., 2018) or the soybean cyst nematode H. glycines (St-Marseille et al., 2018; Wang et al., 2015). However, to our knowledge, no study has been conducted to describe the genetic structure of the carrot cyst nematode Heterodera carotae, except two recent studies using genic markers with a diagnostic purpose (Escobar-Avila et al., 2018; Madani et al., 2017).

H. carotae was first reported in England in 1931 and described by Jones in 1950 and is distributed worldwide (see Subbotin et al., 2010 for a review). It causes remarkable yield losses to carrot in Europe (Greco et al., 1993; Mugniery and Bossis, 1988) and in the USA (Berney and Bird, 1992). It has been recently described in Canada (Yu et al., 2017). A contrario to its sister species $H$. cruciferae, $H$. carotae is highly specific and develop on the genera of Daucus and Torilis (Aubert, 1986) and only controlled since decades with chemical nematicides which are banned today. The time frame and geographic regions of the first domestication of its cultivated host, Daucus carota L. subsp sativus Hoffm., remain still unclear. However, it has been generally accepted that wild carrots, which are indigenous of Europe and Central Asia, are the ancestors of domesticated carrots (i.e. cultivated), and that cultivated carrots are originated from Central Asia during the $10^{\text {th }}$ century (Grzebelus et al., 2014; Iorizzo et al., 2013). Then, carrot crops spread in Europe between the $11^{\text {th }}$ and $15^{\text {th }}$ centuries. The orange-rooted carrots, the most recent evolution of cultivated carrots, are probably the result of selection in the early $17^{\text {th }}$ century. Finally, orange carrots spread from Europe to other continents such as North America (Baranski et al., 2012).

Over the last decades, microsatellite markers have proved to be good candidates for investigating the population genetic structure of nematodes because these markers are highly polymorphic, codominant and broadly neutral (Selkoe and Toonen, 2006). Microsatellites, also known as simple sequence repeats (SSR), consist of motifs of one to six nucleotides tandemly repeated in different frequencies among populations. 
The goals of this study were 1) to develop polymorphic microsatellite markers amplifiable in all $H$. carotae populations and 2) to investigate, for the first time, the genetic structure of $H$. carotae populations at the European scale.

\section{MATERIAL AND METHODS}

\subsection{Nematode populations}

Eighteen populations of the carrot cyst nematode, $H$. carotae, were collected at the field spatial scale (10 samplings randomized in the field) and multiplied on the cultivar "Carottes nantaises" (Vilmorin) in greenhouse for this study. Thirteen of these populations were sampled in fields in France, one in Italy, one in Switzerland, two in Denmark and the last one was sampled outside Europe in a field in Canada. Cyst were extracted from soil samples by a Kort elutriator and stored at $5^{\circ} \mathrm{C}$ in moistened sandy soil.

\subsection{DNA extraction}

One J2 from forty cysts was used for each population (i.e. 720 individuals). An extraction procedure using sodium hydroxide, adapted from Stanton et al. (1998) was conducted. Each $\mathrm{J} 2$ was incubated at room temperature overnight in $20 \mu \mathrm{L}$ of $\mathrm{NaOH} 0.25 \mathrm{M}$ in microtube. Tubes were then centrifuged at 3,700 rpm during $3 \mathrm{~min}$ and incubated in a thermocycler at $99^{\circ} \mathrm{C}$ for $2 \mathrm{~min}$ before the addition of $20 \mu \mathrm{L}$ of lysis buffer $(10 \mu \mathrm{L} \mathrm{HCl} 0.25 \mathrm{M}, 5 \mu \mathrm{L}$ Tris $\mathrm{HCl}$ $0.5 \mathrm{M} \mathrm{pH} 8,5 \mu \mathrm{L}$ Triton X100 2\%) follow by incubation for $2 \mathrm{~min}$ at $99^{\circ} \mathrm{C}$. Subsequently, 10

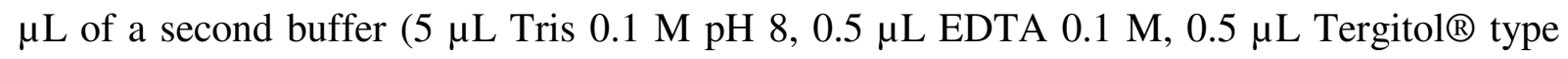
NP-40, $0.25 \mu \mathrm{L}$ Proteinase $\mathrm{K}$ at $20 \mathrm{mg} / \mathrm{mL}$, adjusted with sterile distilled water) were added and the tubes were incubated at $55^{\circ} \mathrm{C}$ for $1 \mathrm{~h}$ and then at $94^{\circ} \mathrm{C}$ for $10 \mathrm{~min}$. Tubes were centrifuged (3,700 rpm, $30 \mathrm{~s})$ and the supernatants were used for PCR. 


\subsection{Microsatellite genotyping}

In order to assess the genetic variability of $H$. carotae populations, 13 polymorphic microsatellite markers (Hc07, Hc29, Hc35, Hc40, Hc49, Hc55, Hc59, Hc63, Hc72, Hc76, Hc87, Hc91 and Hc94) were developed according to the procedure developed by Malausa et al. (2011) using library enrichment and next generation sequencing. All the details regarding the choice and the development of the microsatellite loci used in this study can be found in the Appendix A. PCR reaction in multiplex contained $5 \mu \mathrm{L}$ of $2 \mathrm{X}$ Type-it Microsatellite PCR kit (Qiagen), $1 \mu \mathrm{L}$ of $2 \mu \mathrm{M}$ primer mix, $2 \mu \mathrm{L}$ of template DNA and $2 \mu \mathrm{L}$ of sterile water distilled. Cycling conditions included an initial denaturation at $95{ }^{\circ} \mathrm{C}$ for $5 \mathrm{~min}$, followed by 30 cycles of denaturation at $95{ }^{\circ} \mathrm{C}$ for $30 \mathrm{~s}$, annealing at $57^{\circ} \mathrm{C}$ for $90 \mathrm{~s}$ and extension at $72{ }^{\circ} \mathrm{C}$ for $30 \mathrm{~s}$, followed by a final extension at $60{ }^{\circ} \mathrm{C}$ for $30 \mathrm{~min}$. PCR products were then diluted 1:40 in sterile water and $3 \mu \mathrm{L}$ of this dilution was mixed with $7.5 \mu \mathrm{L}$ of GeneScan $500 \mathrm{LIZ}$ Size Standard: formamide (Applied Biosystems) $=1: 100$ (volume ratio). Analysis of PCR products were conducted on ABI 3730XL sequencer (GENTYANE Platform, INRA, ClermontFerrand, France). Allele size determinations were achieved using the GeneMapper software v5.0 (Applied Biosystems) by manual identification of peaks. A second round of PCR and electrophoresis was performed for $10 \%$ of the global number of individuals. Among the 720 individuals, 665 are successfully genotyped and this dataset was used for all genetic analyses except for STRUCTURE analysis.

\subsection{Data analysis}

Linkage disequilibrium between loci was calculated using GENEPOP 4.0.7 (Raymond, 1995), with default Markov chain parameters, to count the number of locus pairs showing significant linkage disequilibrium across all populations. A Bonferroni correction (adjusted $\alpha=0.0006$ for 78 comparisons) was applied to take into account multiple testing. Null allele frequencies 
were estimated for each locus across all populations using the likelihood-based method of Chybicki and Burczyk (2009) implemented in the INEst program.

To investigate the genetic diversity, unbiased estimates of gene diversity (Hnb according to Nei (1978)) and allelic richness (Ar) were estimated for each population using respectively GENETIX 4.05.2 (Belkhir et al, 2004) and the rarefaction method (El Mousadik and Petit, 1996) implemented in POPULATION 1.2.32 (Langella, 1999). Deviations from random mating $\left(F_{\text {IS }}\right)$ were computed for each population using GENETIX 4.05.2, and significances of $F_{\text {IS }}$ were tested using the allelic permutation method (10,000 permutations).

To explore the genetic structure of $H$. carotae individuals without taking into account their geographic origin, the Bayesian clustering algorithms implemented in STRUCTURE 2.3.4 (Falush et al., 2003; Pritchard et al., 2000) were run on a dataset without missing data (i.e. 320 individuals), in order to obtain the best assignment for each individuals (Lombaert et al., 2018; Smith and Wang, 2014). Following the recent recommendations of Wang (2017), and because the sizes of samples from the different populations were unbalanced, the alternative ancestry prior, a nondefault ALPHA value (i.e. 1/p with $\mathrm{p}$ being the number of populations) and the uncorrelated allele frequency model were used. Simulations were performed using the admixture model. $H$. carotae individuals were assigned to $\mathrm{K}$ genetic clusters, with $\mathrm{K}$ varying from 1 to 19 (i.e. $\mathrm{p}+1$ ). For each assumed $\mathrm{K}$ value, thirty independent runs were conducted to assess the consistency of the results across runs, and each run was based on $3 \times 10^{6}$ iterations after a burn-in period of $1 \times 10^{6}$ iterations. The most likely number of genetic clusters $(\mathrm{K})$ was statistically determined using the ad-hoc Evanno statistic $\Delta \mathrm{K}$ (Evanno et al., 2005). To confirm the accuracy of individual assignments provide by STRUCTURE, a principal component analysis (PCA) was also performed using the procedure available in the package adegenet (Jombart, 2008) for the statistical freeware $\mathrm{R}$ 
version 3.4.3 (R Core Team, 2017). Individuals from each obtained genetic clusters were then used to explore the substructure within each cluster following the same procedure. Genetic differentiation coefficients $\left(F_{\mathrm{ST}}\right)$ were estimated using GENEPOP 4.5.1 according to Weir and Cockerham (1984) for each pair of populations. Patterns of isolation by distance (IBD) were tested by calculating the correlation between the matrices of pairwise genetic distances $\left(F_{\mathrm{ST}} /\left(1-F_{\mathrm{ST}}\right)(\right.$ Slatkin, 1995) and the natural logarithm of geographic distance for each pair of populations in the entire dataset and within each genetic cluster (Rousset, 1997). The statistical significance of correlations was assessed with a Mantel test (10,000 permutations) using XLSTAT 2018.7 (Addinsoft SARL, Paris, France).

\section{RESULTS}

\subsection{Genetic diversity of $\mathrm{H}$. carotae populations}

Among the 665 genotyped individuals from the eighteen $H$. carotae populations, our set of 13 microsatellites markers allowed the identification of 63 distinct alleles, with two to nine alleles per locus (Table 1). Only three locus pairs (Hc55 - Hc87, Hc59 - Hc87 and Hc40 Hc59) among the 78 pairs showed a significant linkage disequilibrium with the Bonferroni's adjustment. The percentage of estimated null allele averaged $8.94 \%$ among all microsatellite markers (Table 1). This low number of null alleles will not have an important effect on the estimations of population differentiation and heterozygote deficit (Carlsson, 2008; Wang et al., 2015).

The allelic richness (Ar) estimated on a reduced sample of fourteen individuals varied between 1.62 and 2.63 alleles per populations. The unbiased heterozygoty (Hnb) ranged from 0.15 to 0.43 . The relationship among the unbiased estimates of gene diversity (Hnb) and the allelic richness showed populations with low diversity $(0.1<\mathrm{Hnb}<0.25$ and $1.5<\mathrm{Ar}<2.0)$, 
which corresponded to populations from Denmark, Canada, Swiss, France (3001 and 0101), and populations with high diversity $(\mathrm{Hnb}>0.3$ and $\mathrm{Ar}>2.0)$ for all the other ones (Figure 1). Among the eighteen populations, only four populations were at the Hardy-Weinberg equilibrium ( $F_{\text {IS not }}$ significantly different to zero), and all the fourteen remaining populations showed a significant positive value of $F_{\text {IS }}$ (from 0.11 to 0.38 ), highlighting heterozygote deficits (Table 2).

\subsection{Genetic structuration and clustering analysis}

Results from the Bayesian clustering analysis showed clearly that, according to the Evanno's $\Delta \mathrm{K}$, the best way to explain the structuration of individuals was to group them into $\mathrm{K}=2$ genetic clusters (Figure 2A). The thirty replicate runs gave the same result. STUCTURE results indicated that $94 \%$ of individuals were very well assigned (with a percentage of assignation to one or the other cluster higher than 90\%), and the genetic differentiation between cluster 1 and 2 was high $\left(F_{\mathrm{ST}}=0.16\right)$. Principal component analysis (PCA) supported the existence of two major genetic clusters (1 and 2) with axis 1 and 2 explaining $27.3 \%$ and $3.1 \%$ respectively of total genetic variability (Figure $2 \mathrm{~B}$ ). Regarding both the geographical position of the seventeen European populations with their cluster's membership highlighted two geographical groups, with a south group corresponding to cluster 1 and a north group corresponding to cluster 2 , even if some individuals of the cluster 1 were located in the north and vice versa (Figure 3). The Canadian population clustered with populations from the northern group (Figure 3).

To see a possible substructure into these two clusters, two other STRUCTURE analyses were performed using individuals from each obtained cluster. The cluster 1 , which contained six populations, divided in two sub-clusters (1a and 1b; Figure 4A), which were supported by PCA results (Figure 4B). The cluster 2, which contained twelve populations 
divided in four sub-clusters $(2 \mathrm{a}, 2 \mathrm{~b}, 2 \mathrm{c}$ and $2 \mathrm{~d}$; Figure $4 \mathrm{C})$, which were supported by PCA results (Figure 4D).

\subsection{Genetic differentiation between H. carotae populations}

At the large spatial scale explored here, the genetic differentiation was significant for all pairs of $H$. carotae populations. The pairwise $F_{\mathrm{ST}}$ values ranged from 0.01 to 0.69 (Figure 5). The lowest pairwise $F_{\mathrm{ST}}$ values were observed between populations from the north group (e.g. between populations 50170, 2902, Cre7, 5601, 4402, 7201 - Figure 5). In the genetic cluster 1, the highest $F_{\mathrm{ST}}$ values were observed for the population ZAP, which is also the most geographically distant. In the genetic cluster 2 , the highest $F_{\mathrm{ST}}$ values were observed for the population 3001, which is geographically distant from other French populations but far less distant than Danish and Canadian populations. However, the relationships between the genetic distance $\left(F_{\mathrm{ST}} / 1-F_{\mathrm{ST}}\right)$ and the $\ln ($ geographic distance) were significantly correlated, either for the entire dataset $\left(\mathrm{r}^{2}=0.09 ; P<0.0001\right)$, or within genetic cluster $2\left(\mathrm{r}^{2}=0.13 ; P<0.0001\right)$, except for genetic cluster $1\left(\mathrm{r}^{2}=0.20 ; P=0.131\right)($ Appendix $\mathrm{B})$.

\section{DISCUSSION}

The present study has provided a set of 13 polymorphic microsatellite markers, multiplexible in four panels, which constitutes a powerful tool to perform population genetics studies in the carrot cyst nematode Heterodera carotae. Moreover, we have performed here the first study of the genetic structure of $H$. carotae populations at the European scale, which highlights a high heterozygote deficit and two distinct genetic clusters in this species.

Among the eighteen $H$. carotae populations, fourteen deviate from the HardyWeinberg equilibrium and show significant positive $F_{\text {IS }}$ values. Such a heterozygote deficit appears to be shared between cyst nematode species, as it has been also described for 
Globodera pallida (Picard et al., 2004), Heterodera schachtii (Plantard and Porte, 2004), G. tabacum (Alenda et al., 2014), H. glycines (Wang et al., 2015) and H. avenae (Wang et al., 2018), which attack respectively potato, sugar-beet, tobacco, soybean and wheat. The cause of this feature is the low active dispersal abilities of nematode juveniles in the soil, which leads either to consanguineous mating (between individuals from the same cyst) or to substructure (Wahlund effect) at the spatial scale of the rhizosphere of a host plant. According to the recent results of Montarry et al. (2015) showing that heterozygote deficits were due to consanguinity for monovoltine species (G. pallida) and to substructure for polyvoltine species (H. schachtii and G. tabacum), we can hypothesize that the heterozygote deficit highlighted in $H$. carotae populations, which performed several generations per year, is mostly due to a Wahlund effect. Samples collected at the plant scale will be helpful now to further disentangle consanguinity from Wahlund effect in the carrot cyst nematode.

Our results showed that $H$. carotae populations are gathered into two genetic clusters. Geographical position of the different genotyped populations showed a clear spatial separation of both clusters, with one group located in the north of Europe and a second one located in the south of Europe, even if some populations included individuals from both genetic clusters. The significant isolation by distance pattern suggests a short-range dispersal among $H$. carotae populations leading to some genetic relationships between the closest populations. Although the Italian population was geographically and genetically distant from the other populations of the cluster 1, the IBD pattern was not significant within this cluster, but this is probably due to the low statistical power (only six populations). Conversely, the IBD pattern was significant within the cluster 2, whereas the most geographically distant populations (i.e. the Danish and the Canadian populations) were not the most genetically distant ones. Altogether, those results reveal i) a gradual migration between the closest populations, mainly due to agricultural practices, which have been showed to contribute to the 
passive dispersion of cyst nematodes (Alenda et al., 2014), and also ii) some events of long distance migration which are more rare events and probably owing to the plant material transfer within a country or among countries. Because the genetic diversity is much smaller for one French population (3001) and for Danish and Canadian populations than for the other populations of the cluster 2, we can hypothesize that those populations were introduced (i.e. sink populations) and came from the north group (i.e. source populations). Moreover, and because the Canadian population clustered with two French populations in the substructure analysis (sub-cluster 2a), contrary to the Danish populations and the population 3001 which were genetically differentiated in the sub-cluster $2 \mathrm{c}$ and $2 \mathrm{~d}$, respectively, the event of introduction in Canada could be more recent, at least in this production area. Moreover, at the spatial scale studied here, $F_{\mathrm{ST}}$ within each cluster were strong ( 0.40 for cluster 1 and 0.32 for cluster 2), indicating low gene flow among populations in each cluster. Nevertheless, previous studies on potato, sugar beet and tobacco cyst nematodes, have reported an important gene flow at a fine-scale (Alenda et al., 2014; Plantard et al., 2008; Plantard and Porte, 2004). Alenda et al. (2014) revealed a leading role of the human activities and more specifically of the transport of soil during harvesting in the passive dispersal of plant-parasitic nematodes. Important soil losses from potato, sugar beet and carrot fields, during harvesting, have been notified (Parlak et al., 2016; Ruysschaert et al., 2007a; Ruysschaert et al., 2007b). In the framework of development of sustainable control strategies such as plant resistances or biocontrol products, studying gene flow at a lower spatial scale may be the next essential step. Population genetic studies may also help in understanding the evolutionary history of pest species. Here, the genetic structure analysis revealed two distinct clusters with the same level of genetic diversity. However, to date, we do not know if the structure observed for nematode populations is the result of the history of cultivated carrots or the history of $H$. carotae on wild carrots with multiple host switches from wild plants to the cultivated ones. 
The first scenario is, with no doubt, the most realistic and simple to explore. Indeed, $H$. carotae is highly specific of cultivated carrots, wild carrots are not natives of North America and the center of domestication has generally been accepted to be Central Asia (Grzebelus et al., 2014; Iorizzo et al., 2013). These arguments support i) a recent introduction of the Canadian population of $H$. carotae in North America, probably through plant commercial exchanges with European countries and ii) for European populations, a colonization of cultivated areas associated with the domestication process, either between the $11^{\text {th }}$ and $15^{\text {th }}$ from the center of domestication or more recently, with the spread of orange carrots. To explore the origin of our both $H$. carotae clusters, some information argue to identify both Afghanistan and Turkey to be two reliable places of domestication and of diversity (Simon, 2000; Stolarczyk and Janick, 2011) where cultivated and wild carrots still cohabit today. It would then require to sample and analyse additional field populations in these regions to determine whether the genetic clusters highlighted here could be found in these potential source populations leading to the description of invasion routes. The second scenario is clearly more difficult to explore. Indeed, even if there is increasing proof that pest species can develop on wild host plants (Gracianne et al., 2014; Monteil et al., 2013; Rouxel et al., 2014), there is no clear evidence of the occurrence of $H$. carotae populations on wild relatives species. Moreover, favouring the scenario of multiple switches from wild host plants to cultivated ones should lead to a more complex genetic structure than the one we observed. Although it may thus represent an extensive and costly effort, sampling wild populations of $H$. carotae on wild relative species may be a first step to strengthen this scenario, which seems to be more speculative. . For both scenarios, new genetic analysis must be done with a new set of populations to determine the possible origin of our two clusters. In the current context of reduction of chemical nematicides, predicting the 
a key challenge. Hence, the description of the genetic diversity and its structuration in space may help to predict the efficiency of new alternative solutions, to design sustainable control strategies (McDonald and Linde, 2002; Pilet-Nayel et al., 2017; Zhu and Zhan, 2012), and from the farmer point of view, to choose the good control solution at the right place. To do so, and rather than working with randomly chosen populations, representative populations of both genetic clusters have to be used in biotest. Thus, we suggest to use the results of the substructure analysis and to test the different control means on six populations belonging to each sub-clusters (sub-clusters 1a, 1b, 2a, 2b, 2c and 2d). Furthermore, we also know that species with large geographical distribution, such as $H$. carotae, are supposed to comprise populations exhibiting different life history traits in response to their adaptation to different local climate conditions (Fournet et al., 2018). A complementary study may be thus to phenotypically characterize $H$. carotae populations from each genetic cluster under different climatic conditions (e.g. different temperatures).

\section{ACKNOWLEDGMENTS}

We gratefully acknowledge Sergei Subbotin for useful comments on a previous version of this paper and Jeremy Clotault for discussion about the history of cultivated carrots. Johannes Hallmann (Institute for Epidemiology and Pathogen Diagnostics - Germany), Lars Møller Roullier and ANRT (Association Nationale Recherche Technologie). (GartneriRådgivningen A/S HortiAdvice Scandinavia - Denmark) and Yu Qing (Agriculture and Agri-Food Canada - Ottawa, Canada) who kindly provided some Heterodera carotae populations were acknowledged. Camille Gautier is supported by $\mathrm{PhD}$ grant from Groupe

\section{Appendix A. Microsatellite marker development}


361 Appendix B. Relationship between the genetic distance $\left(F_{\mathrm{ST}} / \mathbf{1}-F_{\mathrm{ST}}\right)$ and 362 In(geographical distance) in Heterodera carotae populations

363 


\section{REFERENCES}

Alenda, C., Montarry, J., Grenier, E., 2014. Human influence on the dispersal and genetic structure of French Globodera tabacum populations. Infection, Genetics and Evolution 27, 309-317.

Aubert, V., 1986. Contribution à l'étude de la biologie d'un parasite de la carotte. Université de Neuchâtel.

Baranski, R., Maksylewicz-Kaul, A., Nothnagel, T., Cavagnaro, P.F., Simon, P.W., Grzebelus, D., 2012. Genetic diversity of carrot (Daucus carota L.) cultivars revealed by analysis of SSR loci. Genetic Resources and Crop Evolution 59, 163-170.

Belkhir K., Borsa P., Chikhi L., Raufaste N. \& Bonhomme F. 1996-2004 GENETIX 4.05, logiciel sous Windows TM pour la génétique des populations. Laboratoire Génome, Populations, Interactions, CNRS UMR 5000, Université de Montpellier II, Montpellier (France).

Berney, M., Bird, G., 1992. Distribution of Heterodera carotae and Meloidogyne hapla in Michigan carrot production. Journal of Nematology 24, 776-778.

Bird, D.M., Kaloshian, I., 2003. Are roots special? Nematodes have their say. Physiological and Molecular Plant Pathology 62, 115-123.

Boucher, A.C., Mimee, B., Montarry, J., Bardou-Valette, S., Bélair, G., Moffett, P., Grenier, E., 2013. Genetic diversity of the golden potato cyst nematode Globodera rostochiensis and determination of the origin of populations in Quebec, Canada. Molecular Phylogenetics and Evolution 69, 75-82.

Carlsson, J., 2008. Effects of microsatellite null alleles on assignment testing. Journal of Heredity 99, 616-623.

Castagnone-Sereno, P., Mulet, K., lachia, C., 2015. Tracking changes in life-history traits related to unnecessary virulence in a plant-parasitic nematode. Ecology and Evolution 5, 3677-3686.

Chybicki, I.J., Burczyk, J., 2009. Simultaneous estimation of null alleles and inbreeding coefficients. Journal of Heredity 100, 106-113. 
El Mousadik, A., Petit, R., 1996. High level of genetic differentiation for allelic richness among populations of the argan tree [Argania spinosa (L.) Skeels] endemic to Morocco. Theoretical and Applied Genetics 92, 832-839.

Escobar-Avila, I.M., Óliver, E., Subbotin, S.A., Tovar-Soto, A., 2018. First report of carrot cyst nematode Heterodera carotae in Mexico: morphological, molecular characterization and host range study. Journal of Nematology 50, 229-242.

Evanno, G., Regnaut, S., Goudet, J., 2005. Detecting the number of clusters of individuals using the software STRUCTURE: a simulation study. Molecular Ecology 14, 2611-2620.

Eves-van den Akker, S., Lilley, C.J., Reid, A., Pickup, J., Anderson, E., Cock, P.J., Blaxter, M., Urwin, P.E., Jones, J.T., Blok, V.C., 2015. A metagenetic approach to determine the diversity and distribution of cyst nematodes at the level of the country, the field and the individual. Molecular Ecology 24, 5842-5851.

Falush, D., Stephens, M., Pritchard, J.K., 2003. Inference of population structure using multilocus genotype data: linked loci and correlated allele frequencies. Genetics 164, 1567-1587.

Fournet, S., Kerlan, M.-C., Renault, L., Dantec, J.-P., Rouaux, C., Montarry, J., 2013. Selection of nematodes by resistant plants has implications for local adaptation and cross-virulence. Plant Pathology 62, 184-193.

Fournet, S., Pellan, L., Porte, C., Piriou, C., Grenier, E., Montarry, J., 2018. Populations of the beet cyst nematode Heterodera schachtii exhibit strong differences in their life-history traits across changing thermal conditions. Frontiers in Microbiology 9, 2801.

Gracianne, C., Fournet, S., Porte, C., Renault, L., Petit, E.J., Rouaux, C., Fouville, D., Arnaud, J.-F., 2014. Spatial distribution and basic ecology of Heterodera schachtii and $H$. betae wild populations developing on sea beet, Beta vulgaris ssp. maritima. Nematology 16, 797-805.

Greco, N., D'addabbo, T., Brandonisio, A., Elia, F., 1993. Damage to Italian crops caused by cystforming nematodes. Journal of Nematology 25, 836-842. 
Grzebelus, D., Iorizzo, M., Senalik, D., Ellison, S., Cavagnaro, P., Macko-Podgorni, A., Heller-Uszynska, K., Kilian, A., Nothnagel, T., Allender, C., 2014. Diversity, genetic mapping, and signatures of domestication in the carrot (Daucus carota L.) genome, as revealed by Diversity Arrays Technology (DArT) markers. Molecular Breeding 33, 625-637.

Holleley, C.E., Geerts, P.G., 2009. Multiplex Manager 1.0: a cross-platform computer program that plans and optimizes multiplex PCR. BioTechniques 46, 511-517.

Iorizzo, M., Senalik, D.A., Ellison, S.L., Grzebelus, D., Cavagnaro, P.F., Allender, C., Brunet, J., Spooner, D.M., Van Deynze, A., Simon, P.W., 2013. Genetic structure and domestication of carrot (Daucus carota subsp. sativus)(Apiaceae). American Journal of Botany 100, 930-938.

Jombart, T., 2008. adegenet: a $\mathrm{R}$ package for the multivariate analysis of genetic markers. Bioinformatics 24, 1403-1405.

Jones, M., Northcote, D., 1972. Nematode-induced syncytium--a multinucleate transfer cell. Journal of Cell Science 10, 789-809.

Kim, J., Ni, G., Kim, T., Chun, J.Y., Kern, E.M., Park, J.K., 2018. Phylogeography of the highly invasive sugar beet nematode, Heterodera schachtii (Schmidt, 1871), based on microsatellites. Evolutionary Applications, 1-13.

Langella, O., 1999. Populations 1.2.31. Population Genetic Software (Individuals or Populations Distances, Phylogenetic Trees) 2012. http://bioinformatics.org/ tryphon/populations/.

Lebarbenchon, C., Brown, S.P., Poulin, R., Gauthier-Clerc, M., Thomas, F., 2008. Evolution of pathogens in a man-made world. Molecular Ecology 17, 475-484.

Lilley, C.J., Atkinson, H.J., Urwin, P.E., 2005. Molecular aspects of cyst nematodes. Molecular Plant Pathology 6, 577-588.

Lombaert, E., Guillemaud, T., Deleury, E., 2018. Biases of STRUCTURE software when exploring introduction routes of invasive species. Heredity 120, 485-499. 
Madani, M., Palomares-Rius, J.E., Vovlas, N., Castillo, P., Tenuta, M., 2017. Integrative diagnosis of carrot cyst nematode (Heterodera carotae) using morphology and several molecular markers for an accurate identification. European Journal of Plant Pathology 150, 1023.

Malausa, T., Gilles, A., Meglecz, E., Blanquart, H., Duthoy, S., Costedoat, C., Dubut, V., Pech, N., Castagnone-Sereno, P., Delye, C., Feau, N., Frey, P., Gauthier, P., Guillemaud, T., Hazard, L., Le Corre, V., Lung-Escarmant, B., Male, P.J., Ferreira, S., Martin, J.F., 2011. High-throughput microsatellite isolation through 454 GS-FLX Titanium pyrosequencing of enriched DNA libraries. Mol Ecol Resour 11, 638-644.

Marché, L., Valette, S., Grenier, E., Mugniéry, D., 2001. Intra-species DNA polymorphism in the tobacco cyst nematode complex (Globodera tabacum) using AFLP. Genome 44, 941-946.

McDonald, B.A., Linde, C., 2002. Pathogen population genetics, evolutionary potential, and durable resistance. Annual Review of Phytopathology 40, 349-379.

Meglécz, E., Costedoat, C., Dubut, V., Gilles, A., Malausa, T., Pech, N., Martin, J.-F., 2010. QDD: a userfriendly program to select microsatellite markers and design primers from large sequencing projects. Bioinformatics 26, 403-404.

Milgroom, M.G., 2015. Population biology of plant pathogens: genetics, ecology and evolution. American Phytopathological Society Press, St. Paul, MN.

Mimee, B., Duceppe, M.O., Véronneau, P.Y., Lafond-Lapalme, J., Jean, M., Belzile, F., Bélair, G., 2015. A new method for studying population genetics of cyst nematodes based on Pool-Seq and genomewide allele frequency analysis. Molecular Ecology Resources 15, 1356-1365.

Molinari, S., 2011. Natural genetic and induced plant resistance, as a control strategy to plantparasitic nematodes alternative to pesticides. Plant Cell Reports 30, 311-323.

Montarry, J., Jan, P.L., Gracianne, C., Overall, A.D., Bardou-Valette, S., Olivier, E., Fournet, S., Grenier, E., Petit, E.J., 2015. Heterozygote deficits in cyst plant-parasitic nematodes: possible causes and consequences. Molecular Ecology 24, 1654-1667. 
Monteil, C.L., Cai, R., Liu, H., Llontop, M.E.M., Studholme, D.J., Morris, C.E., Vinatzer, B.A., 2013. Nonagricultural reservoirs contribute to emergence and evolution of Pseudomonas syringae crop pathogens. New Phytologist 199, 800-811.

Mugniery, D., Bossis, M., 1988. Heterodera carotae Jones, 1950. 1. Gamme d'hôtes, vitesse de développement, cycle. Revue de nématologie 11, 307-313.

Nei, M., 1978. Estimation of average heterozygosity and genetic distance from a small number of individuals. Genetics 89, 583-590.

Nicol, J.M., Turner, S.J., Coyne, D., Den Nijs, L., Hockland, S., Maafi, Z.T., 2011. Current nematode threats to world agriculture, Genomics and molecular genetics of plant-nematode interactions. Springer Science+Business Media B.V. , pp. 21-43.

Niere, B., Krüssel, S., Osmers, K., 2014. Auftreten einer außergewöhnlich virulenten Population der Kartoffelzystennematoden. J Kult 66, 426-427.

Oka, Y., Koltai, H., Bar-Eyal, M., Mor, M., Sharon, E., Chet, I., Spiegel, Y., 2000. New strategies for the control of plant-parasitic nematodes. Pest Management Science: formerly Pesticide Science $56,983-988$.

Parlak, M., Palta, Ç., Yokuş, S., Blanco-Canqui, H., Çarkacı, D.A., 2016. Soil losses due to carrot harvesting in south central Turkey. Catena 140, 24-30.

Perry, R.N., 1986. Physiology of hatching, Cyst nematodes. Springer, pp. 119-131.

Phillips, M., Blok, V., 2008. Selection for reproductive ability in Globodera pallida populations in relation to quantitative resistance from Solanum vernei and S. tuberosum ssp. andigena CPC2802. Plant Pathology 57, 573-580.

Picard, D., Plantard, O., Scurrah, M., Mugniery, D., 2004. Inbreeding and population structure of the potato cyst nematode (Globodera pallida) in its native area (Peru). Molecular Ecology 13, 2899-2908. 
Picard, D., Sempere, T., Plantard, O., 2007. A northward colonisation of the Andes by the potato cyst nematode during geological times suggests multiple host-shifts from wild to cultivated potatoes. Molecular Phylogenetics and Evolution 42, 308-316.

Pilet-Nayel, M.-L., Moury, B., Caffier, V., Montarry, J., Kerlan, M.-C., Fournet, S., Durel, C.-E., Delourme, R., 2017. Quantitative resistance to plant pathogens in pyramiding strategies for durable crop protection. Frontiers in Plant Science 8, 1838.

Plantard, O., Picard, D., Valette, S., Scurrah, M., Grenier, E., Mugniéry, D., 2008. Origin and genetic diversity of Western European populations of the potato cyst nematode (Globodera pallida) inferred from mitochondrial sequences and microsatellite loci. Molecular Ecology 17, 22082218.

Plantard, O., Porte, C., 2004. Population genetic structure of the sugar beet cyst nematode Heterodera schachtii: a gonochoristic and amphimictic species with highly inbred but weakly differentiated populations. Molecular Ecology 13, 33-41.

Pritchard, J.K., Stephens, M., Donnelly, P., 2000. Inference of population structure using multilocus genotype data. Genetics 155, 945-959.

R Core Team (2017). R: A language and environment for statistical computing. R Foundation for Statistical Computing, Vienna, Austria. URL https://www.R-project.org/.

Raymond, M., 1995. GENEPOP (version 1.2): population genetics software for exact tests and ecumenicism. J. Hered. 86, 248-249.

Rousset, F., 1997. Genetic differentiation and estimation of gene flow from F-statistics under isolation by distance. Genetics 145, 1219-1228.

Rouxel, M., Mestre, P., Baudoin, A., Carisse, O., Delière, L., Ellis, M.A., Gadoury, D., Lu, J., Nita, M., Richard-Cervera, S., 2014. Geographic distribution of cryptic species of Plasmopara viticola causing downy mildew on wild and cultivated grape in eastern North America. Phytopathology $104,692-701$. 
Ruysschaert, G., Poesen, J., Auerswald, K., Verstraeten, G., Govers, G., 2007a. Soil losses due to potato harvesting at the regional scale in Belgium. Soil Use and Management 23, 156-161.

Ruysschaert, G., Poesen, J., Wauters, A., Govers, G., Verstraeten, G., 2007b. Factors controlling soil loss during sugar beet harvesting at the field plot scale in Belgium. European Journal of Soil Science 58, 1400-1409.

Selkoe, K.A., Toonen, R.J., 2006. Microsatellites for ecologists: a practical guide to using and evaluating microsatellite markers. Ecology Letters 9, 615-629.

Simon, P.W., 2000. Domestication, historical development, and modern breeding of carrot. Plant Breeding Reviews 19, 157-190.

Slatkin, M., 1995. A measure of population subdivision based on microsatellite allele frequencies. Genetics 139, 457-462.

Smith, O., Wang, J., 2014. When can noninvasive samples provide sufficient information in conservation genetics studies? Molecular Ecology Resources 14, 1011-1023.

St-Marseille, A.-F.G., Lord, E., Véronneau, P.-Y., Brodeur, J., Mimee, B., 2018. Genome scans reveal homogenization and local adaptations in populations of the soybean cyst nematode. Frontiers in Plant Science 9, 987.

Stanton, J., McNicol, C., Steele, V., 1998. Non-manual lysis of second-stage Meloidogyne juveniles for identification of pure and mixed samples based on the polymerase chain reaction. Australasian Plant Pathology 27, 112-115.

Stolarczyk, J., Janick, J., 2011. Carrot: history and iconography. Chronica Horticulturae 51, 13-18.

Subbotin, S.A., Mundo-Ocampo, M., Baldwin, J.G., 2010. Systematics of cyst nematodes (Nematodes: Heteroderinae), Volume 8, Part B. Leiden, The Netherlands, Brill.

Wang, H.-M., Zhao, H.-h., Chu, D., 2015. Genetic structure analysis of populations of the soybean cyst nematode, Heterodera glycines, from north China. Nematology 17, 591-600.

Wang, J., 2017. The computer program structure for assigning individuals to populations: easy to use but easier to misuse. Molecular Ecology Resources 17, 981-990. 
Wang, X., Ma, J., Liu, H., Liu, R., Li, H., 2018. Development and characterization of EST-derived SSR markers in the cereal cyst nematode Heterodera avenae. European Journal of Plant Pathology $150,105-113$.

Weir, B.S., Cockerham, C.C., 1984. Estimating F-statistics for the analysis of population structure. Evolution 38, 1358-1370.

Xhaard, C., Barres, B., Andrieux, A., Bousset, L., Halkett, F., Frey, P., 2012. Disentangling the genetic origins of a plant pathogen during disease spread using an original molecular epidemiology approach. Molecular Ecology 21, 2383-2398.

Xhaard, C., Fabre, B., Andrieux, A., Gladieux, P., Barres, B., Frey, P., Halkett, F., 2011. The genetic structure of the plant pathogenic fungus Melampsora larici-populina on its wild host is extensively impacted by host domestication. Molecular Ecology 20, 2739-2755.

Yu, Q., Ponomareva, E., Van Dyk, D., McDonald, M., Sun, F., Madani, M., Tenuta, M., 2017. First Report of the Carrot Cyst Nematode (Heterodera carotae) From Carrot Fields in Ontario, Canada. Plant Disease 101, 1056-1056.

Zaheer, K., Fleming, C., Turner, S., 1993. Distribution and frequency of occurrence of potato cyst nematode pathotypes in Northern Ireland. Plant Pathology 42, 609-616.

Zhu, W., Zhan, J., 2012. Population genetics of plant pathogens. eLS. John Wiley \& Sons, 1-7. 
Fig. 1. Graphical representation of populations in term of allelic richness and gene diversity.

559

560

Allelic richness (Ar), in x-axis was obtained by using de rarefraction method implemented in population software with a reduced sample size of 14 individuals. Gene diversity (Hnb) was estimated by using the unbiased estimate of Nei (1978). The most diverse populations were in top right corner and the less diverse populations were in the bottom left corner of the graph.

Fig. 2. (A) Clustering results of all $H$. carotae individuals by STRUCTURE. Each sample is indicated by a bar divided in $\mathrm{K}=2$ colored section showing the individual's membership for each clusters. Vertical dotted bars separate individuals from different populations which are indicated below. (B) Scatter plot of the first two principal components of the same data used for the Bayesian clustering analyses. Groups corresponding to the different clusters are plotted using the same colours as in (A).

Fig. 3. Geographical location of the eighteen $H$. carotae populations with their membership proportion of clusters. The colours are the same as Figure $2 \mathrm{~A}$ and correspond to $\mathrm{K}=2$. The diameter of the circle corresponds to the allelic richness.

Fig. 4. Sub-clustering results of cluster 1 (A) and cluster 2 (C) H. carotae individuals by STRUCTURE. Each sample is indicated by a bar divided into K clusters represented by different colours. Vertical dotted bars separate individuals from different populations which are indicated below. 
579 Scatter plot of the first two principal components of the same data used for the Bayesian 580 clustering analyses for cluster 1 (B) and for cluster 2 (D). Groups corresponding to the 581 different sub-clusters are plotted using the same colours as in (A) for $K=2$ and (C) for $K=4$. 582

583 Fig. 5. Matrix of pairwise $F_{\mathrm{ST}}$ between $H$. carotae populations. The distribution of pairwise $584 \quad F_{\mathrm{ST}}$ into cluster 1 and cluster 2 is represented by the box plots.

585 


\begin{tabular}{|c|c|c|c|c|c|c|}
\hline Code & Primer left sequence & Primer right sequence & Motif & Size (bp) & Nbr of allele & Null allele (\%) \\
\hline Hc07 & GCAGAATAGACGTCCACTAGCA & GAAAGAAAGATATAGCCAAAAGCG & (tgtc)5 & 140 & 2 & 4.07 \\
\hline Hc29 & TGTTTGATTGGATTCCCTGG & CAGTTGAATGGTTTTGTGGG & (acag)6 & 145 & 4 & 0.00 \\
\hline Hc35 & GCGCCACCTTTTGATGTTAT & CAATTTAAGGAATAAGCGAAAGAA & (ct) 8 & 103 & 2 & 0.01 \\
\hline Hc40 & CGTCCAGTCTCTTTTCGTTT & ATTTGTTCAGCTTTTATTTGACCG & $(\mathrm{ag}) 8$ & 190 & 4 & 11.71 \\
\hline Hc49 & ATAATGAAAAGCGAGGGGCT & GCATCACCCATTTCCTTTTGT & $(\operatorname{ag}) 6$ & 106 & 3 & 0.00 \\
\hline Hc55 & GTGGGCGTCGTCAAATCAT & ACATTGTTATCAGAGGCAAATCA & (gt) 5 & 140 & 3 & 7.95 \\
\hline Hc59 & ACAAGTCGTGTCCACTTCCC & TGTGATTTTGTATGGCATAGGTG & (ct) 5 & 158 & 7 & 14.97 \\
\hline Hc63 & ATCGTTGAGAAGTTTATTTTGCTTG & CTACGCCCAAAAGGTCAAAA & (ac) 8 & 140 & 8 & 9.48 \\
\hline Hc72 & CCCTTAATGGTTTTCTCAACTG & AGTATGTGGTTGCCGAAGAA & (ct)7 & 141 & 5 & 17.88 \\
\hline Hc76 & AGCTTGCGATGAGTCTCCTG & ATCGCTATGGTGATGCCAA & $(\operatorname{tg}) 7$ & 145 & 6 & 0.00 \\
\hline Hc87 & TTAATCCTTTTGGATGAGATATTGG & CTTTCGAGTGCACACCCTG & (tc)7 & 140 & 9 & 18.51 \\
\hline Hc91 & GCATTATGTTTGCTTTGCCA & TTGATCAAATCGGCATGCTA & $(\mathrm{ag}) 7$ & 133 & 5 & 28.70 \\
\hline Hc94 & CTGGGGCGAAACTTTTATGA & TTTGGTTAATATTGGAATGAATGC & (ac)9 & 101 & 5 & 2.92 \\
\hline
\end{tabular}


589 Table 2: Sampling site, population code, number of genotyped individuals per population (n)

590 and deviation from random mating $\left(F_{\text {IS }}\right) . F_{\text {IS }}$ significantly higher than zero are indicated with 591 an asterisk.

592

593

\begin{tabular}{|c|c|c|c|}
\hline Country & Code & $n$ & $F_{\text {is }}$ \\
\hline France. Ain & 0101 & 37 & $0.109 *$ \\
\hline France. Bouches du Rhône & 1302 & 38 & $0.183^{*}$ \\
\hline France. Bouches du Rhône & 1303 & 40 & $0.224 *$ \\
\hline France. Finistère & 2902 & 40 & $0.246 *$ \\
\hline France. Gard & 3001 & 40 & 0.039 \\
\hline France. Loire Atlantique & 4401 & 35 & $0.375^{*}$ \\
\hline France. Loire Atlantique & 4402 & 39 & $0.224 *$ \\
\hline France. Manche & 50170 & 40 & $0.223 *$ \\
\hline France. Morbihan & 5601 & 36 & 0.045 \\
\hline France. Mayenne & 7201 & 34 & $0.137^{*}$ \\
\hline France. Vaucluse & 8401 & 39 & $0.252 *$ \\
\hline Switzerland & $\mathrm{FU}$ & 40 & $0.178 *$ \\
\hline Italy & ZAP & 38 & $0.274^{*}$ \\
\hline France. Créance & Cre7 & 39 & -0.022 \\
\hline Canada. Ontarrio & Can1 & 14 & $0.327^{*}$ \\
\hline Denmark. Odsherred & Dan1 & 38 & 0.077 \\
\hline Denmark. Holbaek & Dk & 38 & $0.118^{*}$ \\
\hline France. Aisne & $\mathrm{HcaO2}$ & 40 & $0.285^{*}$ \\
\hline
\end{tabular}


$594 \quad$ Figure 1

595

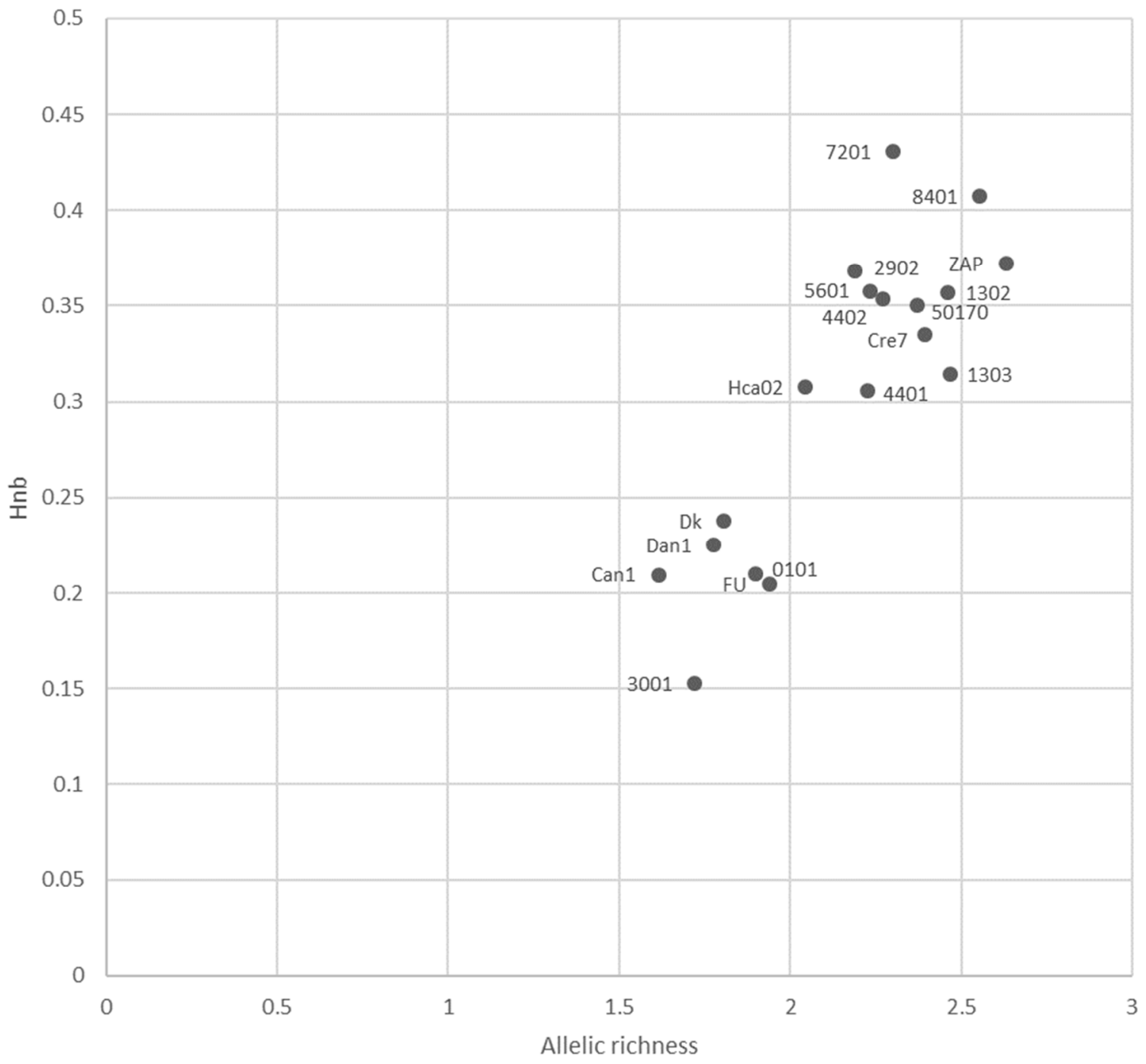

596 
Figure 2

598

599

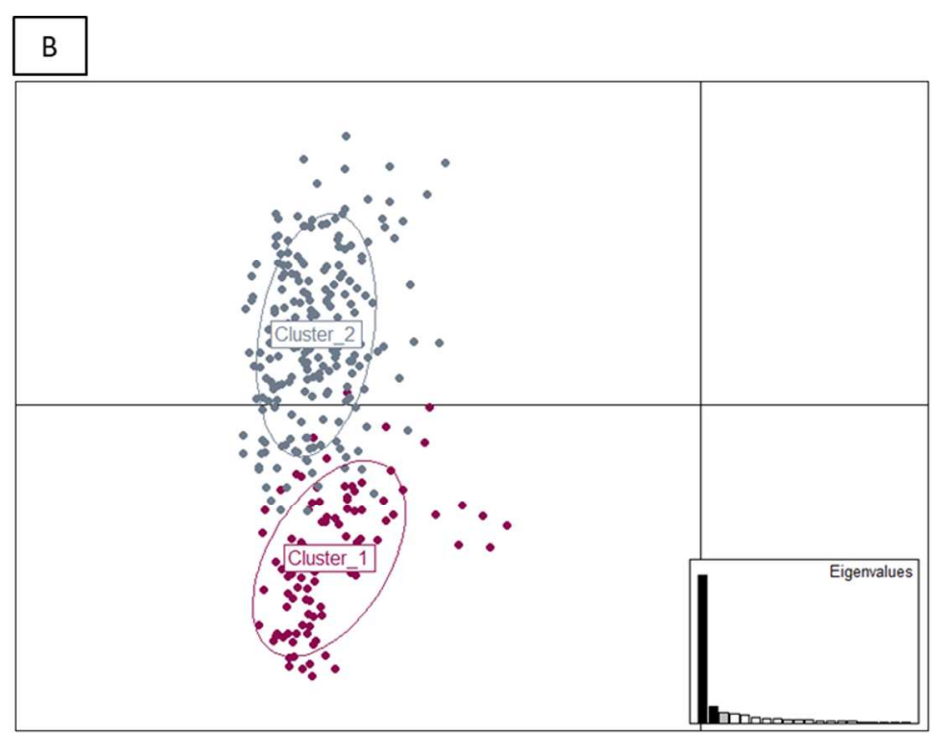


601

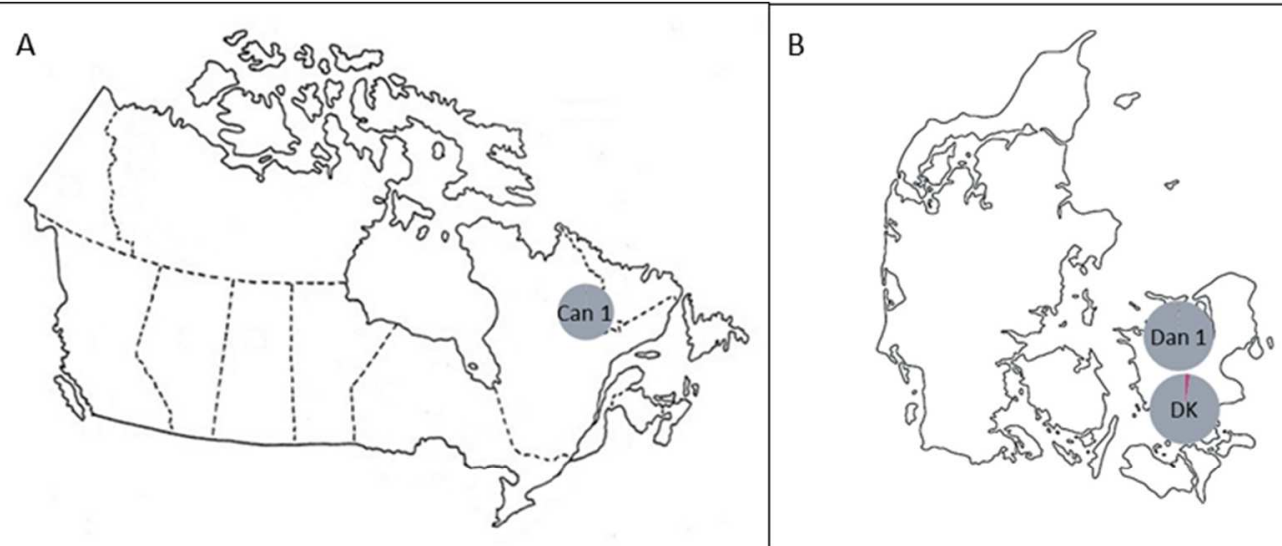

C

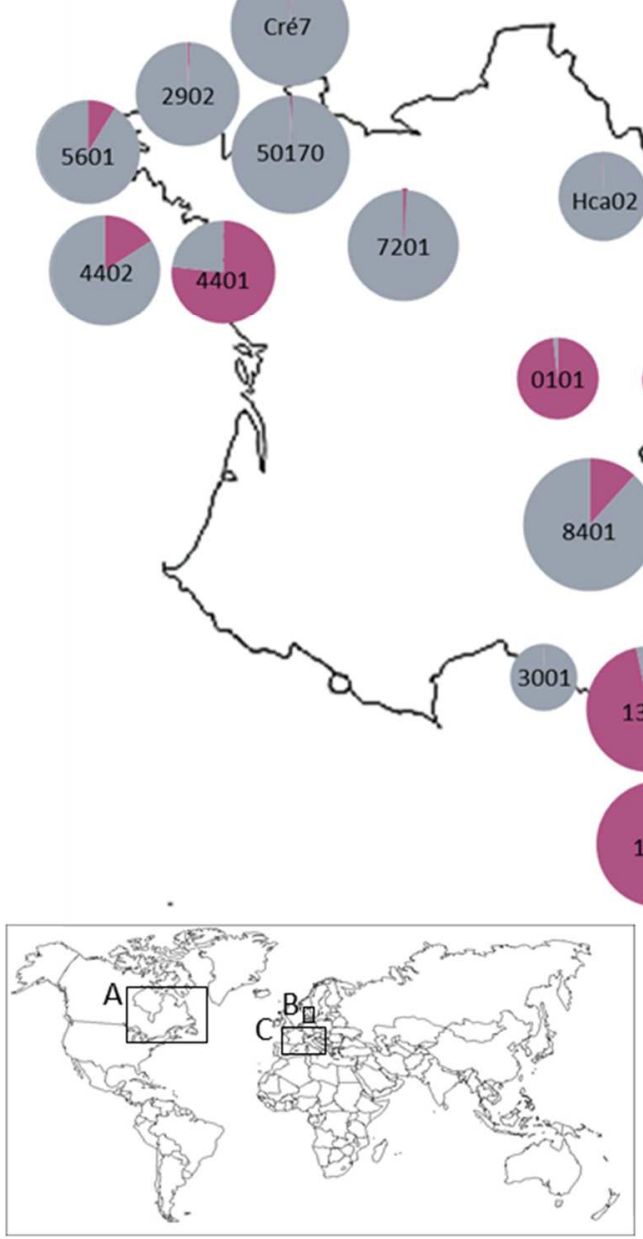


603

604

605

606

Figure 4

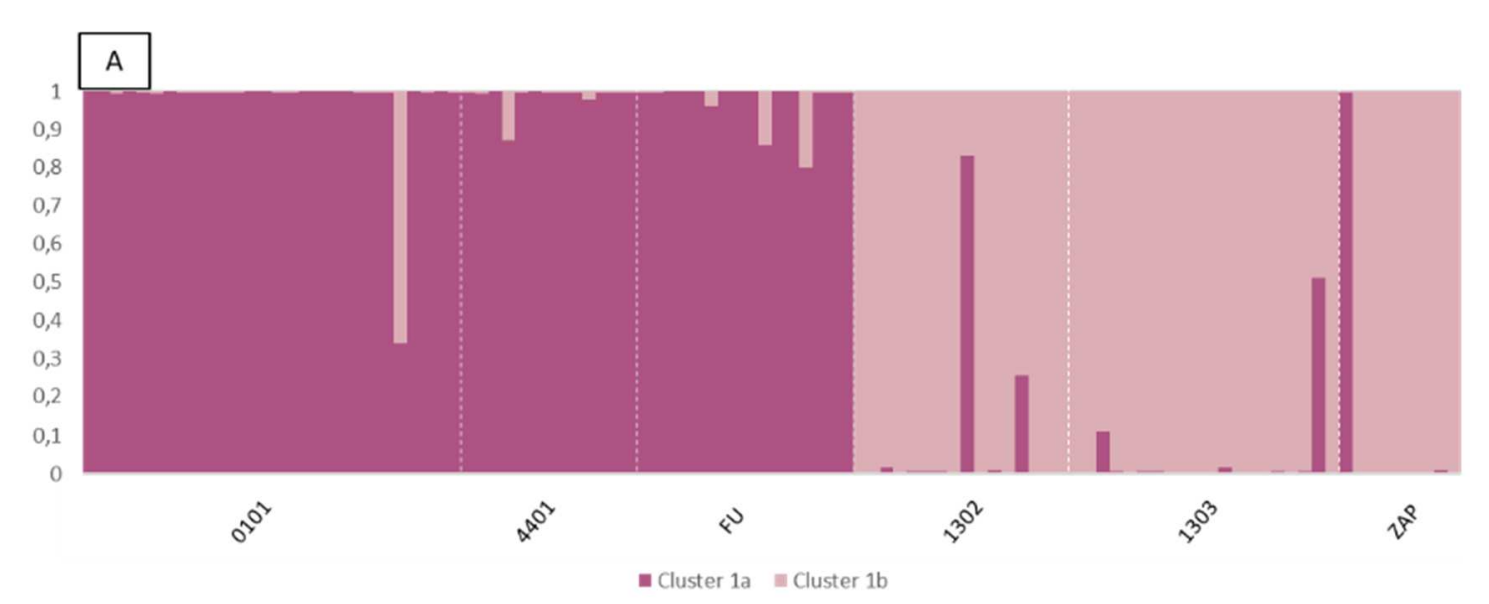

B

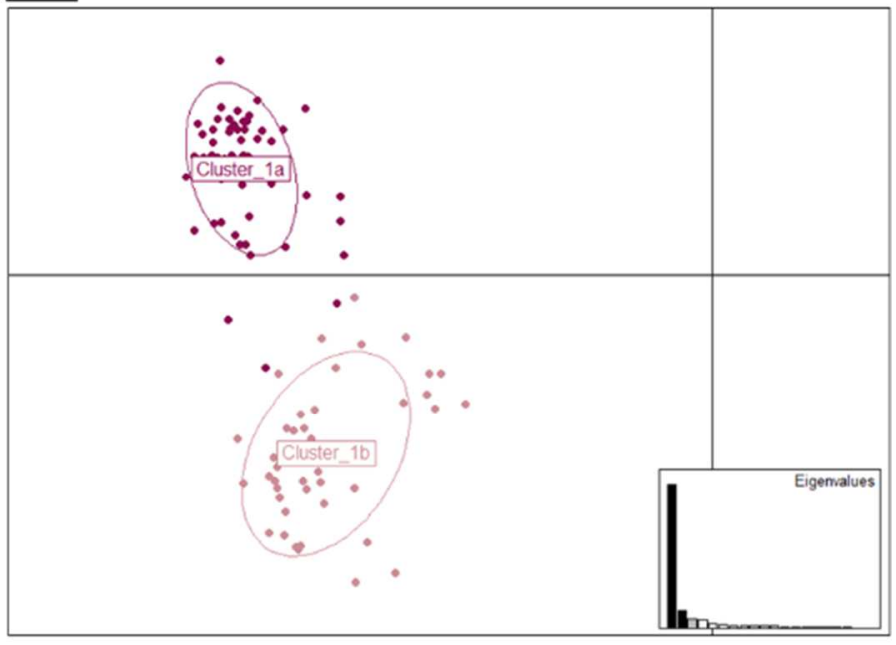

\section{D}

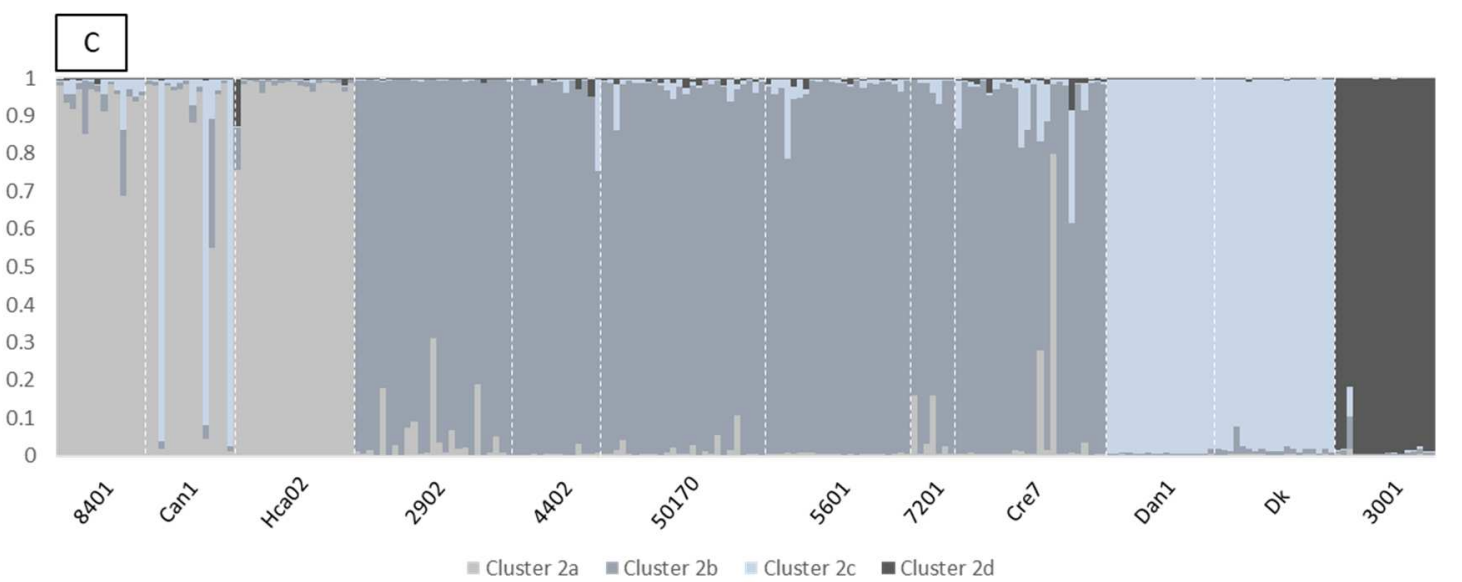

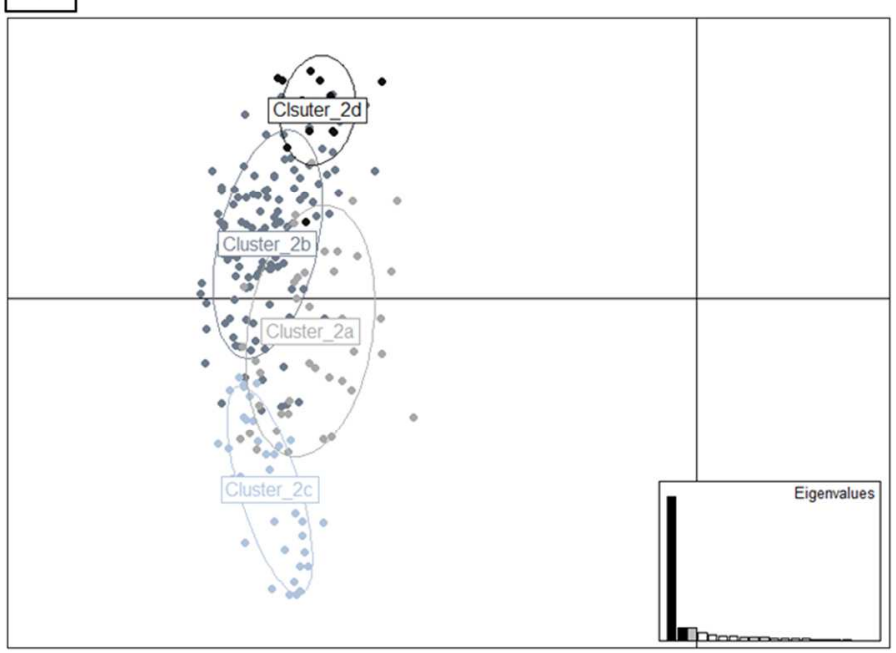


Figure 5

608
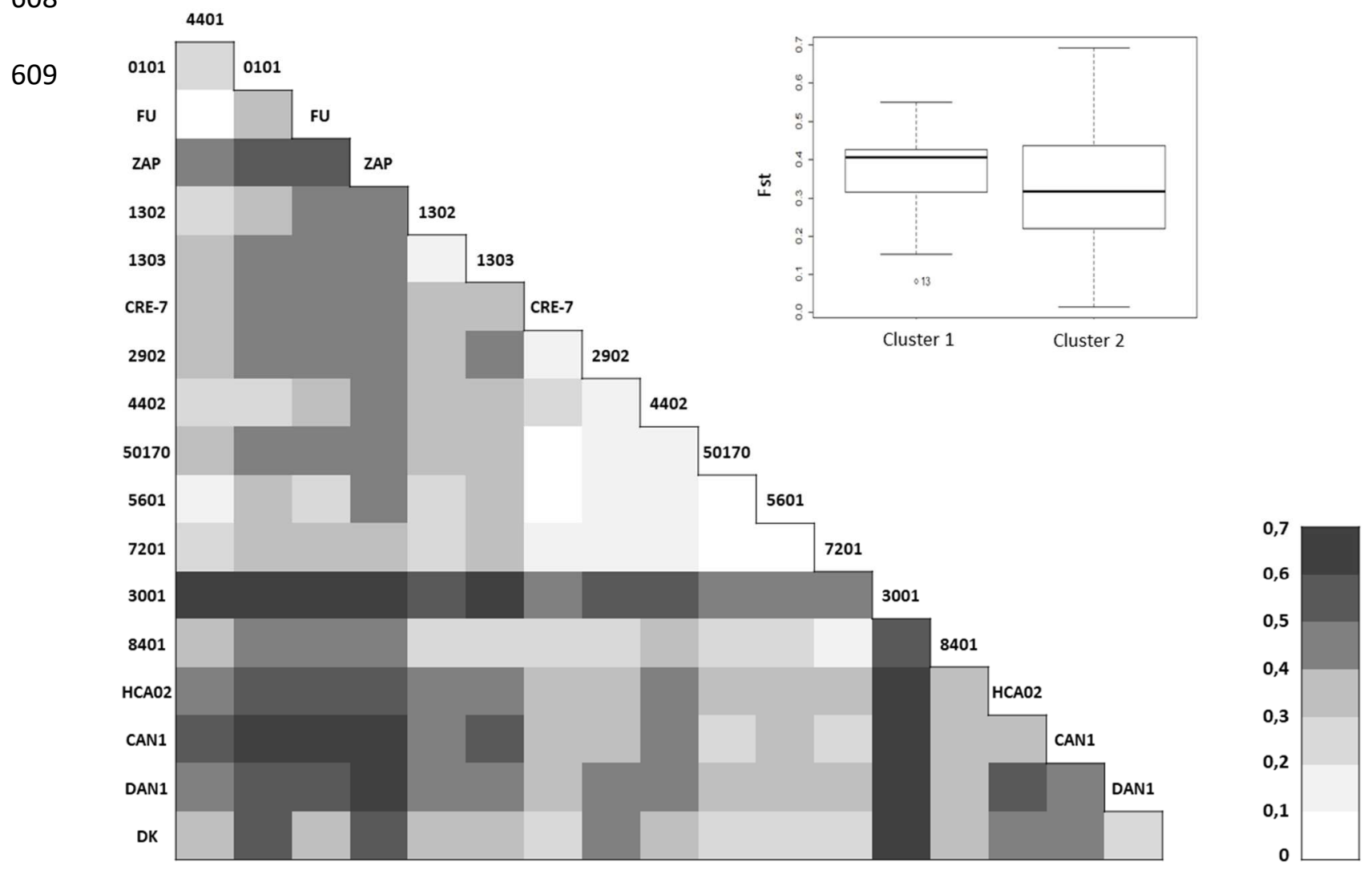


\section{Appendix A. Microsatellite marker development}

Microsatellite markers were developed according to the procedure described by Malausa et al. (2011) using next-generation sequencing and library enrichment. Twelve Heterodera carotae populations $(0101,1303,3001,4401,4402,5601,7201,8401$, FU, ZAP, Hca02, which were then also used for the genetic structure analysis, and 5001, a population from the north-west of France [Manche], which has been lost before the genetic structure analysis) were used to identify microsatellite markers. DNA of each population was extracted from 100 cysts using a DNeasy Blood \& Tissue kit (QIAGEN) and pooled altogether. Enriched libraries were constructed employing eight microsatellites probes ((TG), (TC), (AAC), (AAG), (AGG), (ACG), (ACAT) and (ACTC)) and were sequenced by Genoscreen (Lille, France) using the 454 GS-FLX titanium pyrosequencing technology (ROCHE Diagnostics).

To explore the 241,190 reads obtained from next-generation sequencing and to design primers for microsatellite amplification, the QDD program (Meglécz et al., 2010) was used. Among those reads, 1,134 sequences harboured microsatellite motifs and primers were successfully defined for 199 of them. We have then discarded all tri-nucleotide motifs, all dinucleotide motifs with less than six repetitions and all the loci showing an amplification size below $92 \mathrm{bp}$, leading to a set of 95 loci with perfect microsatellite motifs.

A biological validation of these loci was carried out on single juveniles (J2) from four populations (3001, 5601, ZAP and FU). The procedure of DNA extraction was described in the main text. A PCR was carried out in a final volume of $10 \mu \mathrm{L}$ using $5 \mu \mathrm{L}$ of $2 \mathrm{X}$ Type-it Microsatellite PCR kit (Qiagen), $0.25 \mu \mathrm{L}$ of $10 \mu \mathrm{M}$ forward primer, $0.25 \mu \mathrm{L}$ of $10 \mu \mathrm{M}$ reverse primer and $2 \mu \mathrm{L}$ of template DNA. Volumes were adjusted to $10 \mu \mathrm{L}$ with sterile water distilled. Cycling conditions included an initial denaturation at $95{ }^{\circ} \mathrm{C}$ for $5 \mathrm{~min}$, followed by 39 cycles of denaturation at $95{ }^{\circ} \mathrm{C}$ for $30 \mathrm{~s}$, annealing at $57^{\circ} \mathrm{C}$ for $90 \mathrm{~s}$ and extension at $72{ }^{\circ} \mathrm{C}$ for $30 \mathrm{~s}$, ended by a final elongation step at $72{ }^{\circ} \mathrm{C}$ during $5 \mathrm{~min}$. The amplification of these 
PCR products was revealed by electrophoresis on a $2 \%$ agarose gel. We discarded loci with no or low amplification and multiband amplification and kept 36 pairs of primers with a good amplification of the four populations.

To explore the reproducibility and the polymorphism of the selected loci, two juveniles from two distinct cysts from the four populations (3001, 5601, ZAP and FU) were used. The forward primer of each pair was tailed with M13F [5'- CAC GAC GTT GTA AAA CGA C -3'] to facilitate labelling. A PCR was realized twice in a final volume of $10 \mu \mathrm{L}$ using $5 \mu \mathrm{L}$ of $2 \mathrm{X}$ Type-it Microsatellite PCR kit (Qiagen), $0.25 \mu \mathrm{L}$ of $10 \mu \mathrm{M}$ fluorescent-labeled M13 primer (VIC, Applied biosystem), $0.25 \mu \mathrm{L}$ of $10 \mu \mathrm{M}$ forward primer, $0.25 \mu \mathrm{L}$ of $10 \mu \mathrm{M}$ reverse primer and $2 \mu \mathrm{L}$ of template DNA. Volumes were adjusted to $10 \mu \mathrm{L}$ with sterile water distilled. Cycling conditions included an initial denaturation at $95{ }^{\circ} \mathrm{C}$ for $5 \mathrm{~min}$, followed by 20 cycles of denaturation at $95{ }^{\circ} \mathrm{C}$ for $30 \mathrm{~s}$, annealing at $57{ }^{\circ} \mathrm{C}$ for $90 \mathrm{~s}$ and extension at $72{ }^{\circ} \mathrm{C}$ for $30 \mathrm{~s}$, followed by 20 cycles of denaturation at $95{ }^{\circ} \mathrm{C}$ for $30 \mathrm{~s}$, annealing at $53{ }^{\circ} \mathrm{C}$ for $90 \mathrm{~s}$, extension at $72{ }^{\circ} \mathrm{C}$ for $30 \mathrm{~s}$ and a final extension at $60{ }^{\circ} \mathrm{C}$ for $30 \mathrm{~min}$. PCR products were then diluted 1:40 in sterile water and $3 \mu \mathrm{L}$ of this dilution was mixed with $7.5 \mu \mathrm{L}$ of GeneScan 500 LIZ Size Standard: formamide (Applied Biosystems) $=1: 100$ (volume ratio). Analysis of PCR products were conducted on ABI 3730XL sequencer (Applied Biosystems). Allele size determinations were achieved using the GeneMapper software v5.0 (Applied Biosystems) by manual identification of peaks. This step allowed to validate a set of 13 polymorphic microsatellite markers showing a reproducible amplification.

Multiplex manager Software (Holleley and Geerts, 2009) was used to define the best combinations of these 13 microsatellites markers for multiplex reactions. Four multiplex combinations (Fig below) were identified and contained between three to four markers (each $2 \mu \mathrm{M})$ per panels with a different fluorescent dye (FAM, VIC, NED, PET). 
661

662

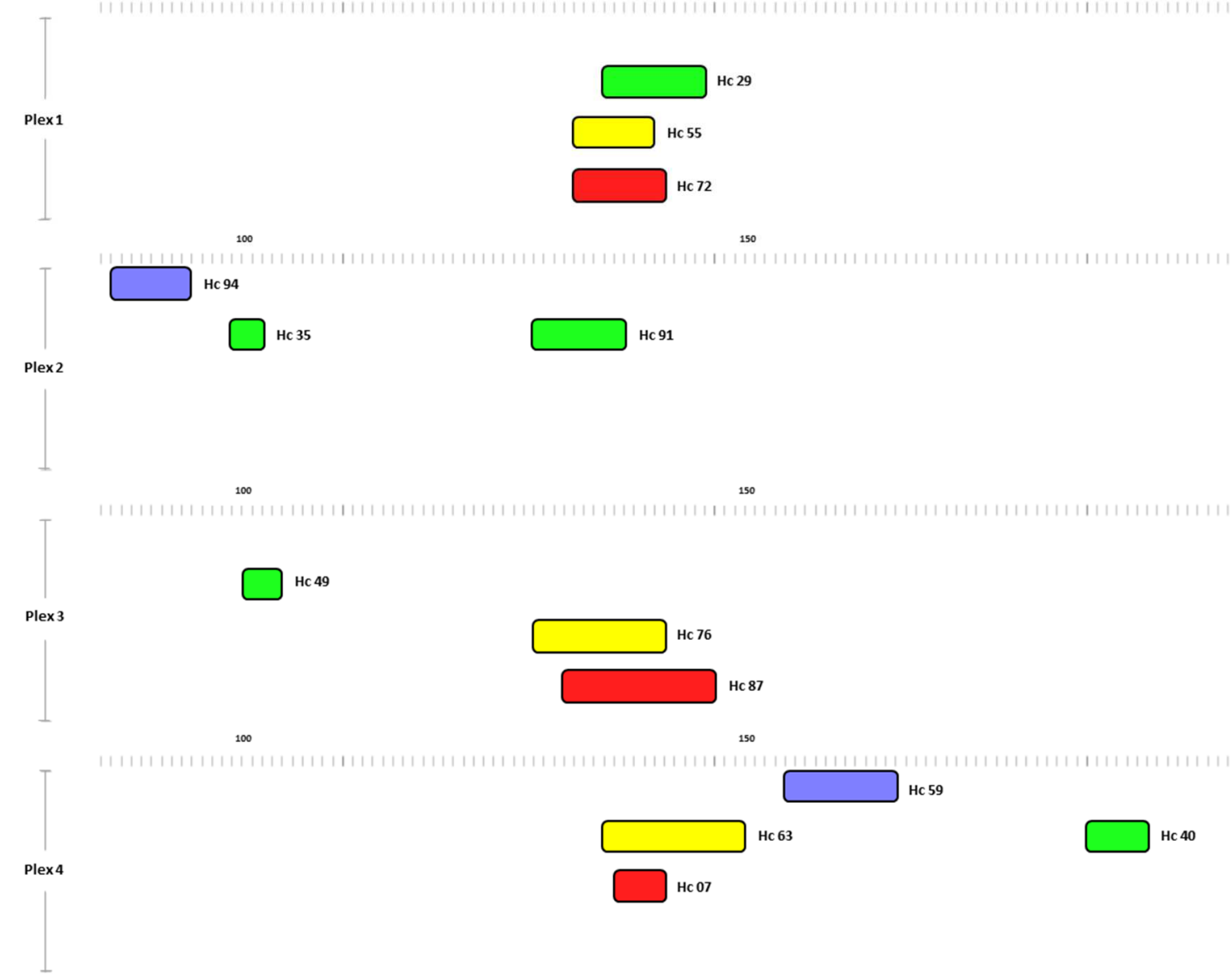

Legend

\begin{tabular}{lll}
\hline 6-FAM & NIC \\
\hline
\end{tabular} 
663

664

665

666

667

668

669

670

671

672

673

Appendix B. Relationship between the genetic distance $\left(F_{\mathrm{ST}} / 1-F_{\mathrm{ST}}\right)$ and $\ln$ (geographical distance) in Heterodera carotae populations for the entire dataset (A), for cluster 1 (B) and for cluster 2 (C).

\section{A}

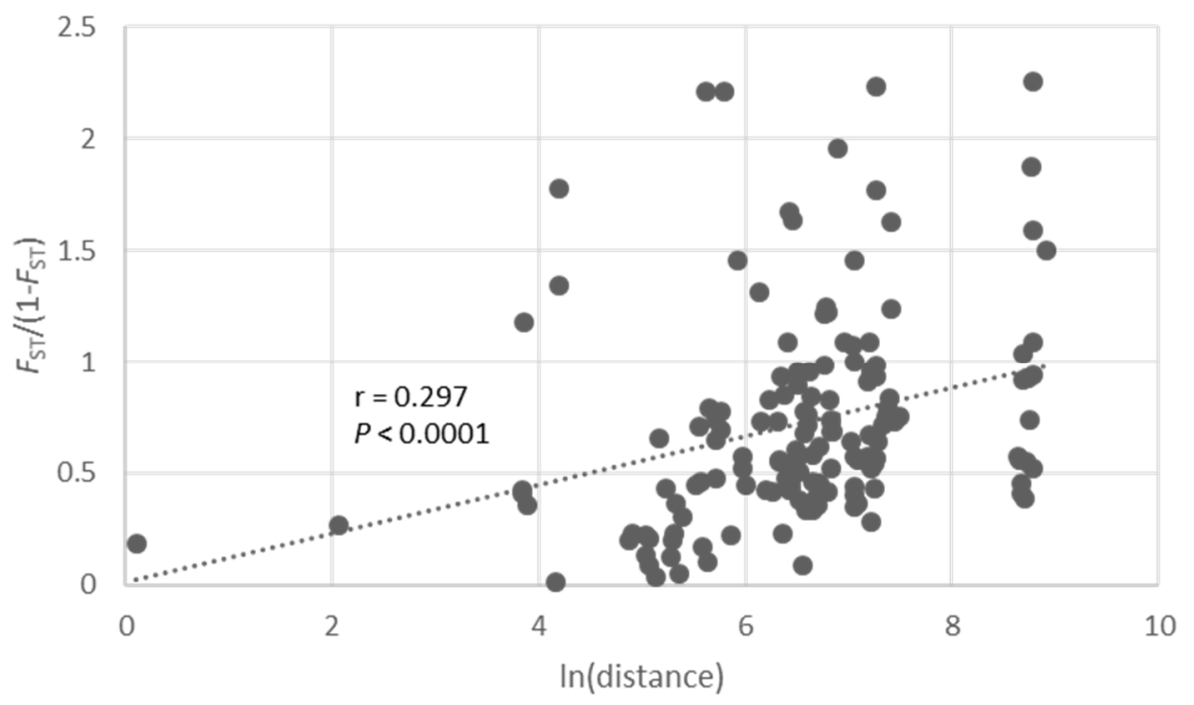

B

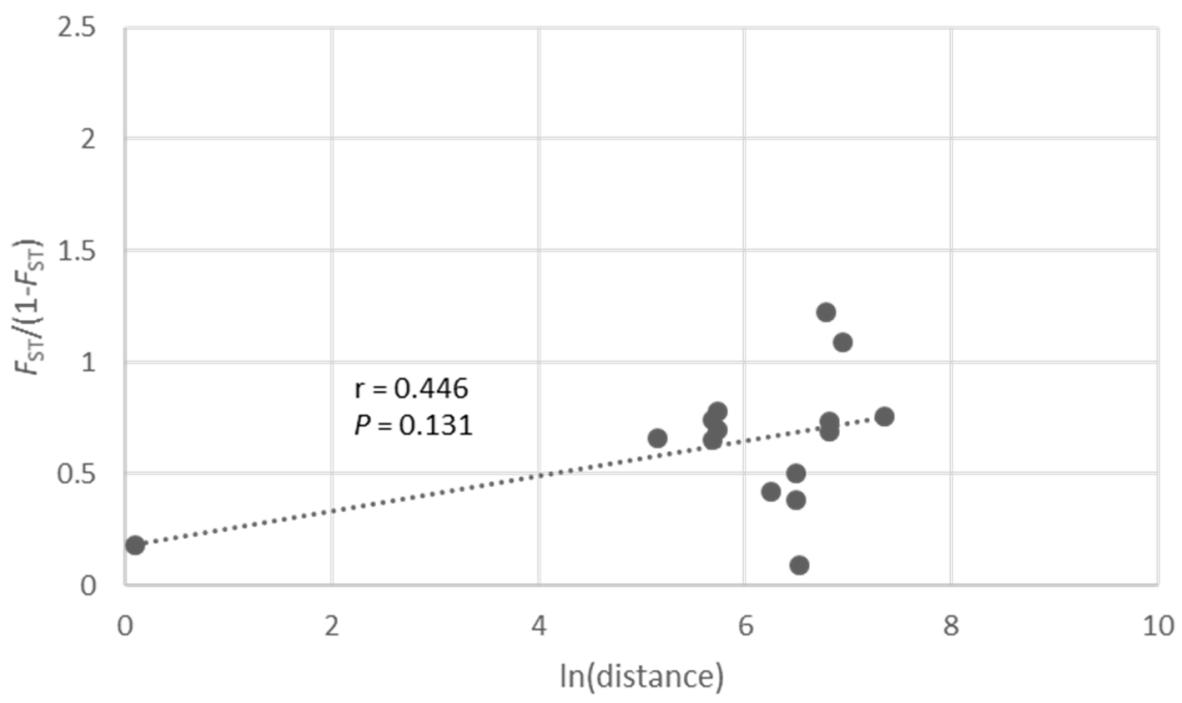


675
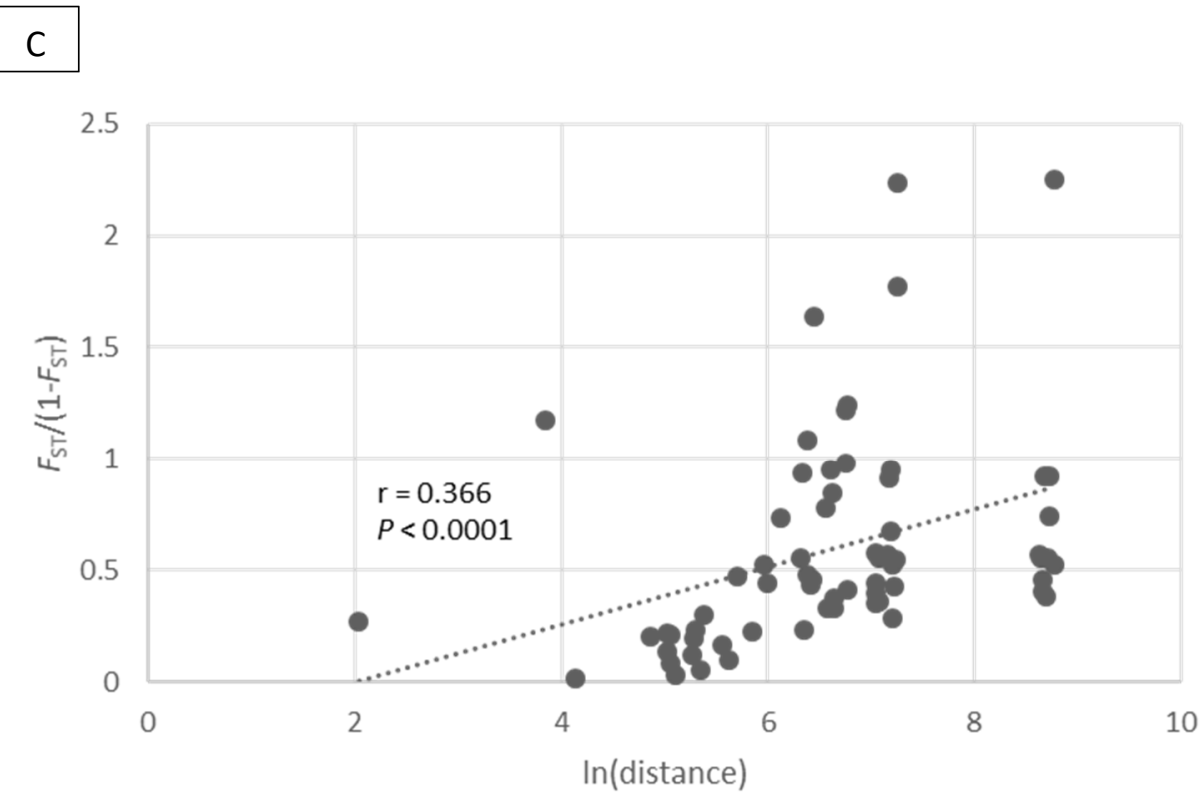

676 


\section{Graphical abstract}

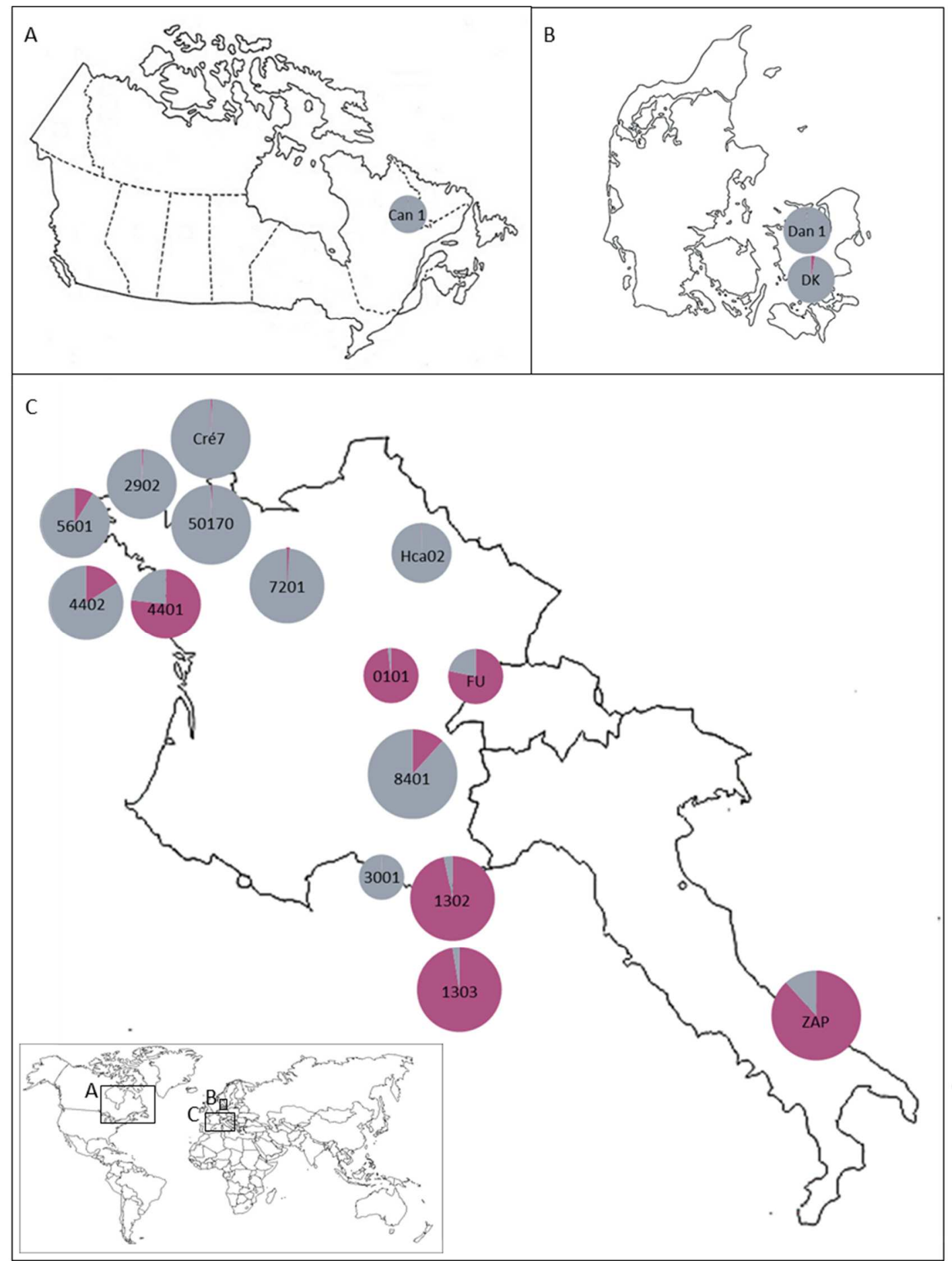

